\title{
In Memorium
}

\section{Arieh Singer \\ (1934-2010)}

\author{
By \\ Dr. Joe B. Dixon \\ Emeritus Professor of Soil Clay Mineralogy \\ Texas A \& M University, College Station, TX 77843
}

Dr. Arieh Singer passed away on March 26, 2010, in Israel after being diagnosed with lung cancer only 4 months before. He was born May 14, 1934, and was happily married for 39 years. $\mathrm{He}$ is survived by his wife, two daughters, one son, and four grandchildren.

Arieh Singer obtained both M.S. and Ph.D. degrees from The Hebrew University of Jerusalem, Rehovot, Israel, and served on the faculty there throughout his career, with interim positions in several other universities in other countries.

$\mathrm{He}$ was an internationally respected soil scientist with special skills and experience in

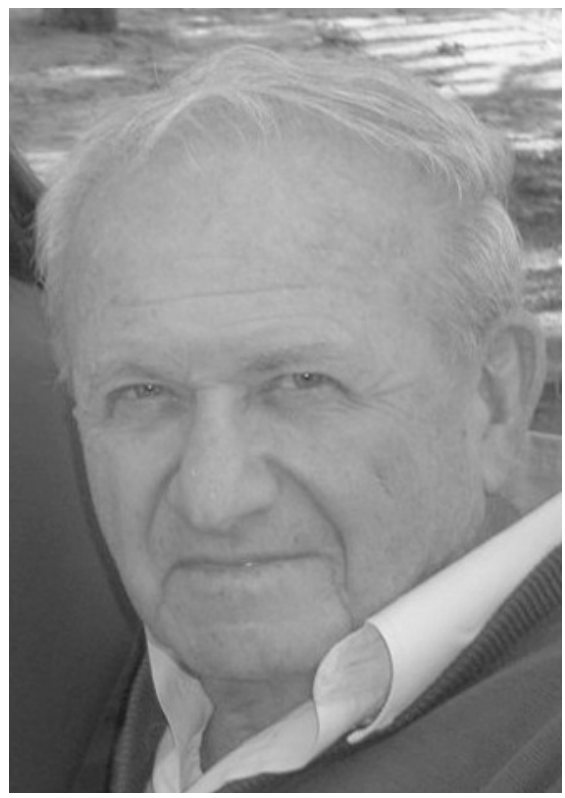
and serves as a guide for studies of soils threatened by population growth and urbanization in Israel and in other parts of the world. His writings also include two chapters on palygorskite and sepiolite minerals in books on soil mineralogy published in 1989 and 2002 by the Soil Science Society of America.

Dr. Singer was professionally active, investigating soil occurrence, formation, and properties in different parts of the world, including Russia and Australia. He also studied the dewatering of phosphatic clays by converting palygorskite to smectite, a persistent environmental problem associated with phosphate mining in Florida, USA. He investigated the formation of palygorskite in sepiolite and attapulgite fibrous clays, common constituents of soils of the Middle East. He wrote the book The Soils of Israel (Springer, 2007) which reflects his intimacy with soils in desert landscapes and the pedological and geological history of Israel. He used this inspiring book to teach soil classification, taking advantage of the book's numerous photos of landscapes, maps, and soil profiles, many of which are in color. His enthusiasm for soils in the landscape is well presented soils of Australia and the occurrence of sepiolite in South Africa. Dr. Singer had a long and creative career that illustrates his enthusiasm for understanding fibrous clays in soils and associated geologic environments.

Like the dust storm over the Negev Desert of Israel pictured in his New Year's greeting card in early 2010 (below), his influence will always be there. His impact on soil science will be lasting.

Received May 31, 2010

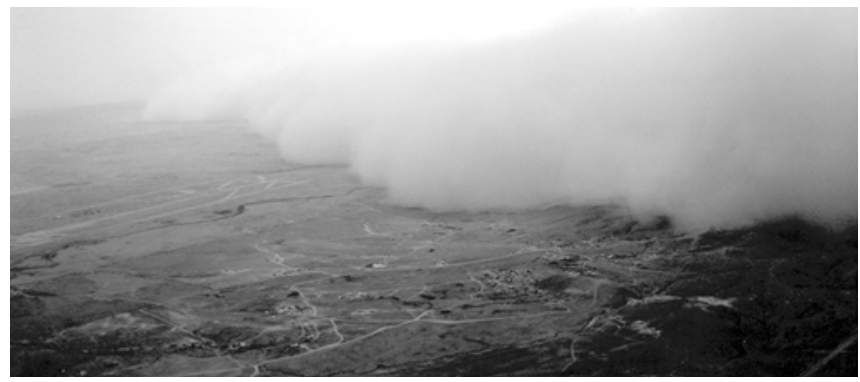

